\title{
The Phonetic Nature of Vowels in Modern Standard Arabic
}

\author{
Mohammad Yahya Bani Salameh \\ Department of English Language and Literature \\ Ajloun National University, Ajloun, Jordan \\ E-mail: mohdbanisalameh@yahoo.com \\ Abdel-Rahman Abu-Melhim (Corresponding author) \\ Department of English Language and Literature \\ Irbid University College, Al-Balqa' Applied University, Irbid, Jordan \\ E-mail: abumelhim@hotmail.com
}

Doi:10.7575/aiac.alls.v.5n.4p.60

Received: $15 / 04 / 2014$

URL: http://dx.doi.org/10.7575/aiac.alls.v.5n.4p.60

Accepted: 17/06/2014

\begin{abstract}
The aim of this paper is to explore the phonetic nature of vowels in Modern Standard Arabic (MSA). Although Arabic is a Semitic language, the speech sound system of Arabic is very comprehensive. Data used for this study were elicited from the standard speech of nine informants who are native speakers of Arabic. The researchers used themselves as informants, they also benefited from three other Jordanians and four educated Yemenis. Considering the alphabets as the written symbols used for transcribing the phones of actual pronunciation, it was found that the pronunciation of many Arabic sounds has gradually diverged from the standard. The study also discussed several related issues including: The phonetic description of Arabic vowels, classification of Arabic vowels, types of Arabic vowels and distribution of Arabic vowels.
\end{abstract}

Keywords: Modern Standard Arabic (MSA), Arabic vowels, Dialectal variation, Vowel distribution, Vowel classification.

\section{Introduction}

The Arabic language is one of the most important languages of the world. With its growing importance in the Arab world and in the international affairs, the importance of Arabic language has reached to greater heights. Since Qur'an, the holy book, was revealed in Arabic, the language has a place of special prestige in all Muslim societies, and therefore more and more Muslims in Asia, central Asia, and Africa are learning the Arabic language, the language of their faith. Moreover, there is a large number of people around the globe who learn this language because of its political importance. The importance of Arabic has also increased because of the prestigious position of the Arab countries in the world of international trade and commerce (Fatihi, 2001).

\subsection{Afro-Asiatic Languages}

Arabic belongs to the Afro-Asiatic languages. The Afro-Asiatic is a tie family of languages covers most of Africa, north of Sahara and the Sahara itself dipping down on the Eastern side of the continent. The AfroAsiatic family of languages is also a major language family of South Western Asia. The family has five branches: Semitic group of languages, Egyptian, Berber, Cushitic and Chadic. After serving for millennia as the language of one of the world's most spectacular civilizations, Egyptian family of languages, comprising Ligypiian, the language of ancient Egypt, has been extinct. The Cushilic and Chadic languages are sufficiently different from each other. Thus, the Semitic family of languages is the most dominating linguistic family among all Afro-Asiatic languages (Fatihi, 2001).

\subsection{Semitic Family of Languages}

Arabic is one of the major languages in the Semitic family. To be more specific, it is an off-shoot of the languages of South West Asia. The name Semitic owes its origin to SHCM, mentioned in chapter X of Book of Genesis. The chapter deals with ARAM, ASHER, and CBER; that is Ramites, Assyrians, and Hebrew. The scholars of theology and history name these groups of people as Semitic Races. Their relation with each other are evident by the close similarity and strong connection among them. Subsequent excavations have brought to light new information about some more races having similar characteristics. Since then, the term Semitic has acquired a wider sense. Arabic belongs to the Southern group of Semitic languages, this group includes the ancient Southern Arabic, with different dialects namely SABAEAN, MINAEAN, QATABANJAN, and HADRAMAWTEAN. They go back to the period extending over the $8^{\text {th }}$ century B.C. 
The oldest texts in Classical Arabic were found in the inscription of ZABAD (512 A.D.), inscription of HARRAN (568 A.D.) and inscription of UMMUL JIMAL (568 A.D.). These lexis alone cannot explain the sublimity of the Classical Arabic as evidenced in Pre-Islamic Arabic poetry. By the $6^{\text {th }}$ century A.D., the Classical language of pre-Islamic poetry had attained a stage of perfection, so much so that it could receive the inimitable Arabic of the holy book AL-QUR'AN. In the $8^{\text {th }}$ century A. D., scholars like AlFaraheedi and Sibawaih got interested in the development of the language and presented their observations in pioneering works like Al-Kitab which is supposed to be one of the greatest monuments of human intelligence.

\subsection{Dialectal Variation}

It can be claimed that Arabic is one of the most important languages of the modern world. A full understanding of the structure of the language may help in establishing the dialectal variation of Arabic. The central concept underlying the term "dialect" lies in the local variations in pronunciation, grammar or vocabulary. Though many criteria have been used for determining the status of a dialect within a speech community, yet, most linguists tend to concentrate on the criterion of "mutual intelligibility". With regard to mutual intelligibility, all the regional varieties of Arabic can be viewed from two spatial dimensions, i.e., lying next to one another and spoken at each end of the language area. In both these situations there is hardly any problem of mutual intelligibility at any level of linguistic expression (Chejne, 1958).

The phonetic peculiarities of different formal styles of pronunciation, including the permissible degree of reduction and assimilation of speech sounds, are also an important criterion for designating a particular speech as a regional variation from other regional styles of the same language. Regional variations in Arabic may be assigned to geographical factors, which had made inter-communication difficult among different regions of the Arab world in the past. Consequently, each region along with many other social and ethnic factors developed its own peculiarities exhibited at different levels of the variety spoken in that area. Moreover, the language contact and inter dialectal borrowings, have contributed to dialectal variations as well. In Arabic, clearer dialectal divisions are obtainable in the areas where mutual intercourse among the people living in different areas is hindered due to physical barriers such as high mountain ranges or wide rivers (Greenberg, 1978).

At present, however, the increasing contact brought in by developed systems of communications, education and urbanization, among the speakers of different dialects of Arabic has greatly affected the speech habits of different regions and consequently, has made the task of demarcation of various dialects very difficult, by minimizing dialectal differences to a greater extent.

\section{Purpose}

The purpose of this study is to highlight the vocalic system in Modern Standard Arabic (MSA). The study further delves into the phonological nature of Arabic vowels with regard to this particular variety, discussing several related issues including: Phonetic description of Arabic vowels, classification of Arabic vowels, types of Arabic vowels and distribution of Arabic vowels.

\section{Methodology}

Data used for this study were elicited from the standard speech of nine informants who are native speakers of Arabic. Furthermore, the researchers used themselves as informants, they also benefited from three other Jordanians and four educated Yemenis whose linguistic behavior is judged to be /faSi:H/ 'clear', 'eloquent' through several successive sittings.

These four Yemenis and three Jordanians are as follows:

- Four Ph.D. candidates at Yarmouk University. (Yemenis)

- Three M.A. students at Yarmouk University. (Jordanians)

\section{Literature Review}

\subsection{Definition of Modern Standard Arabic (MSA)}

A fully agreed - upon definition of MSA does not yet exist, but there is a general consensus that modern Arabic writing in all its forms constitutes the basis of the identity of the language. Modern writing, however, covers an extensive range of discourse styles and genres ranging from complex and conservative to innovative and experimental. Finding a standard that is an identifiable segment of the modern Arabic writing language used for media purposes, and it has been the focus of linguists' attention for a number of years because of its stability, its pervasiveness, and its ability to serve as a model of contemporary written usage (Abboud, 1984). Dissemination of a written (and broadcast) prestige standard by the news media is a wide-spread phenomenon, especially in multilingual, diglossic, and multi-dialectal societies.

Elsaid Badawi's phrase fuSHâ al-âsr (فصدى العصر) is his Arabic term for MSA (1985, p. 17), which he locates on a continuum (at "level two").

As he points out, the levels "are not segregated entities", $(1985$, p. 17) but shade into other levels gradually. He identifies level two (MSA) as "mostly written" rather than spoken, and levels two and three 
as essentially "in complementary distribution" with each other (1985, p. 19) that is, they function in separate spheres, with some overlap (Karin, 2006).

\subsection{Arabic Phonology}

The speech sound system of Arabic is very comprehensive. Considering the alphabets as the written symbols used for transcribing the phones of actual pronunciation, it has adequately covered the maximum number of sounds available in other languages. The human vocal system of articulator apparatus is a complete musical device and the elegance of this system has manifested itself to the fullest extent in the Arabic phonology. Thus, there are some sounds which are exclusively found only in the Arabic phonological system and not in any other language, such as /D/,/DH/,/S/,/T/, although, we may come across some similar sounds there, but these are not well defined and distinguished from the aspect of articulation. If we consider that the primary task of phonology is to provide an objective description of speech, then the sound symbols or notational symbols of Arabic phonology are efficient description of possible variety of articulation and sound patterns.

Keeping in view the arbitrary nature of linguistics, one remarkable fact about pronunciation is that it is in a continuous process of alteration generation after generation. This process is natural and many factors, ranging from the individual psychological to the social factors, play their role in the change. This is a universal law of nature; therefore, no phonological system of any language is immune to change.

Speech sounds are a perpetual target of change and variation. The process involves many factors which have an implosive and arbitrary nature. It is to be observed in principle that to determine the trends of this variation is not an easy task because the process seems to be such a slow and complex and takes a long natural course before it attracts the attention of observers and researchers. Departing from this point, we notice that the pronunciation of many Arabic sounds has gradually diverged from the standard towards many colloquial dialects.

Apart from these minor developments in some regional dialects of the Arabic language, the phonological base of standard Arabic resisted any change. This is exceptional in case of the Arabic language, as no other language ever could maintain the consistency of its phonological sequences.

\subsection{Introducing Arabic Vowels}

Vowels are speech sounds in the articulation of which, the regressive air stream from the lungs issues into the open air without meeting any closure or such constriction as would cause audible friction in the oral as well as the pharyngeal cavities. In the articulation of vowels, the highest part of the tongue which varies is located within a certain zone in the oral cavity which may be described as the vowel area. Phoneticians assume a vowel to be voiced by definition, however, some of them consider some languages to have voiceless vowels (Abercrombie, 1967).

\subsubsection{Classification of Arabic Vowels}

The Arabic vocalic system mainly revolves around six vowels and two diphthongs. Arab phoneticians have recognized six pure vowels out of which three are long and the other three are short. A detailed description of these vowels is given below.

In the phonetic description of the Arabic vowels, it may be noted that three degrees of height of the tongue are recognized, (Crothers, 1978). Examples are illustrated in the following table:

Table 1. Degrees of height of the tongue

\begin{tabular}{lll}
\hline Close & i: & u: \\
\hline Half close & I & U \\
\hline Open & a: & \\
\hline
\end{tabular}

With regard to the position of the tongue in the production of Arabic vowels, three places are recognized. They are:

Table 2. Tongue positions

\begin{tabular}{llll}
\hline Front & i: & I & \\
\hline Central & a & & \\
\hline Back & u: & U & a: \\
\hline
\end{tabular}

With regard to the length, Arabic vowels are categorized into short and long vowels. Short vowels are further divided into: fatha, kasra, and damma. Fatha is indicated by a small diagonal stroke above the preceding consonantal speech sound. Kasra is the similar stroke below the consonantal speech sound. 
Damma is like a miniature "waw" above the preceding consonantal speech sound. A chart of short and long vowels of Arabic is given below:

Table 3. Arabic short and long vowels

\begin{tabular}{llll}
\hline Short Vowels & I & U & a \\
\hline Long Vowels & i: & u: & a: \\
\hline
\end{tabular}

On the basis of the lip position, Arabic vowels are classified into unrounded and rounded vowels. In Arabic, front and central vowels are generally recognized as unrounded vowels because they are articulated without any rounding of lips. The Arabic back vowels with an exception of /a:/ are rounded in nature because in their articulation lip-rounding is quite noticeable.

As a result of the above discussed phonetic variations, a six-vowel system consisting of two sub systems, short vowels and corresponding long vowels is identified in Arabic which can be presented (Lindan, 1978), diagrammatically as shown below.

\subsubsection{Types of Arabic Vowels}

The major types of Arabic vowels may be summarized as illustrated in the following table:

Table 4. Articulatory positions

\begin{tabular}{llll}
\hline & Front & Central & Back \\
\hline High & i: & & u: \\
\hline Low-high & $\mathrm{I}$ & $\mathrm{U}$ \\
\hline High-mid & & & \\
\hline Low & & a : \\
\hline Diphthongs of Arabic & ai (ay) & au(aw) \\
\hline
\end{tabular}

It may be concluded from the above table that:

1. The vowels are eight in number: 3 are short, they are $/ \mathrm{i} /, / \mathrm{u} /$ and $/ \mathrm{a} /$ and 3 are long, they are /i:/,/u:/, /a:/ and two diphthongs namely, /aw/ and /ay/. Short and long vowels

2. show a triangular system as follows:

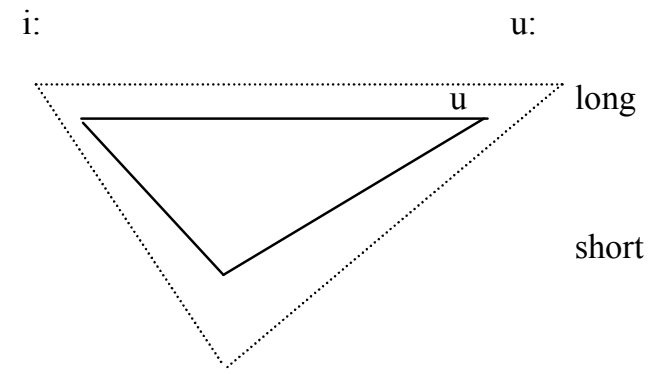

a

a:

3. There are also cases of free variation, where two sounds may be substituted one for the other in particular words without a change of meaning. Thus, while the distinction between the vowels [i] and [a] is phonemic in /Sahr/ 'melting and / Sihr/ 'brother-in-law', the substitution of one for the other in [sami'a] and [sama'a] 'he heard', [dihk] and 'Dahk' 'laugh' is not phonemic. The same applies to $/ \mathrm{a} / \mathrm{and} / \mathrm{u} /$, where the distinction between them in $\left[\mathrm{Du}{ }^{\circ} \mathrm{F}\right]$ and [da'f] 'weakness'.

\section{Discussion}

\subsection{General Description of Arabic Vowels}

There is no definite place of articulation for vowels. Instead, vowels are described according to three parameters as follows:

1. The position of the soft palate, which is raised in Arabic vowels to produce oral vowels.

2. The shape assumed by the lips - rounded or unrounded. 
3. The part of tongue that is raised and how high (Clements, 1991).

A. Short vowels
/a/ Central un-rounded
/i/ High front un-rounded
$/ \mathrm{u} / \quad$ High back rounded

B. Long vowels
/a:/ Low central un-rounded
/i:/ High front un-rounded
/u:/ High back rounded

\subsection{Distribution of Arabic Vowels}

There is a restriction on the occurrence of the vowels in the initial word position.

Al-Ani (1970) writes:

Almost all vowels, when recorded are initiated with a glottal stop. Such an initial glottal stop seems reasonable since all words in Arabic which are normally considered to begin with a vowel usually are initiated with a glottal stop before the vowel (p. 12).

Therefore, vowels occur in the medial and final positions. The ownership forms are the simplest examples to show the occurrence of short and long vowels in the final position.

Table 5. Vowel distribution

\begin{tabular}{|c|c|}
\hline Final position & \\
\hline Unreduced forms & Reduced forms \\
\hline$\underline{\mathrm{Da}}:$ & $\underline{\mathrm{Da}}$ \\
\hline Di: & $\underline{\mathrm{Di}}$ \\
\hline$\underline{\mathrm{Du}}:$ & $\underline{\mathrm{Du}}$ \\
\hline \multicolumn{2}{|l|}{ Medial position } \\
\hline ğild & 'skin' \\
\hline qatl & 'killing' \\
\hline qufl & 'lock' \\
\hline ki:s & 'sack' 'purse' \\
\hline na:r & 'file' \\
\hline nu:r & 'light' \\
\hline
\end{tabular}

\subsection{Phonetic Description of Arabic Vowels}

/i:/: It is a front close vowel. The lips are generally spread. The position of the soft palate is raised and vocal cords are made to vibrate. /i:/ is a long vowel, which is generally pronounced with a considerable muscular tension (Wright, 1977). It occurs in words:

Table 6. Manner of articulation for /i:/

\begin{tabular}{ll}
\hline /rĭ̆1/ & 'foot' \\
\hline /̆gadi:d/ & 'new' \\
\hline /Tawi:1/ & 'long' \\
\hline /Oaqi:1/ & 'heavy' \\
\hline /xi:ra/ & 'good choice' \\
\hline /qari:b & 'near' \\
\hline
\end{tabular}

/i/: It is a short counterpart of the long, front, close, unrounded vowel. In the articulation of this Arabic vowel the lips are generally spread. it occurs in Arabic words like: 
Table 7. Manner of articulation for $/ \mathrm{i} /$

\begin{tabular}{ll}
\hline /inta/ & 'you' \\
\hline /min/ & 'who' \\
\hline /Ha:mi/ & 'warm' \\
\hline /iHna:k/ & 'there' \\
\hline$/$ lisa:n/ & 'tongue' \\
\hline /bunni/ & 'brown' \\
\hline /ibn/ & 'son \\
\hline
\end{tabular}

/u:/: In Arabic, /u:/ is a back, rounded, high, long, vowel. In the articulation of this vowel the lips are generally protruded. Its frequency is fairly high in all types of words and environments (Holes, 1990). The examples are:

Table 8. Manner of articulation for $/ \mathrm{u}: /$

\begin{tabular}{ll}
\hline$/$ tu:b/ & 'repent \\
\hline /masru:r/ & 'pleased' \\
\hline /hudu:d/ & 'frontiers' \\
\hline /su:r/ & 'fence' \\
\hline
\end{tabular}

/u/: It is a lower-high back rounded lax vowel in Arabic. It is the short counterpart of the long back high vowel /u:/. In Arabic, it is commonly known as Dammah. It occurs in Arabic words like:

Table 9. Manner of articulation for $/ \mathrm{u} /$

\begin{tabular}{ll}
\hline /sudd/ & 'dominate' \\
\hline /kursi:/ & 'chair' \\
\hline Kutub & 'books' \\
\hline Durğ & 'drawer' \\
\hline Ouqb & 'hole' \\
\hline
\end{tabular}

/a/: It is a central unrounded vowel in Arabic. It is a short vowel, and is commonly known as fatha in Arabic. /a/ is generally considered as the short counterpart of back, low, unrounded, long vowel /a:/ (Hualde, 1991). It is used in Arabic words like:

Table 10. Manner of articulation for $/ \mathrm{a} /$

\begin{tabular}{ll}
\hline /bass/ & 'enough' \\
\hline$/$ tall/ & 'hill' \\
\hline /xadd/ & 'cheek' \\
\hline
\end{tabular}

/a:/: It is a back, low, unrounded, long, vowel in Arabic. It is almost identical with the English vowel /a:/ as used in English words like - 'alm' and 'calm'. It is less tense and slightly lower than the cardinal vowel/a:/. It occurs in all environments. Its occurrence is shown in the examples below:

Table 11. Manner of articulation for /a:/

\begin{tabular}{ll}
\hline /Da:t/ & 'self' \\
\hline$/$ kIta:b/ & 'book' \\
\hline$/$ fa:di:/ & 'redeem' \\
\hline$/$ xa:li/ & 'empty' \\
\hline$/$ ma:l/ & 'money' \\
\hline
\end{tabular}




\subsection{Arabic Diphthongs}

Most traditional accounts of the Arabic sound system posit/ai/ and/au/ as underlying diphthongs. The process of diphthongization is closely related to vowel clustering (Clements, 1991). The two diphthongs in Arabic are raising diphthongs, in the sense that they end in high vowels $/ \mathrm{i} /$ and $/ \mathrm{u} /$. The two diphthongs are used in words like:

Table 12. Examples of Arabic diphthongs

\begin{tabular}{ll}
\hline /ai/ & \\
\hline bayt/ or /bait & 'house \\
\hline /au/ & \\
\hline yawm/ or /yaum & 'day' \\
\hline
\end{tabular}

\subsection{Distribution of Arabic Diphthongs}

The diphthongs occur in the final and medial positions. In order to be a diphthong in the medial position, it should be immediately followed by a semi-vowel or a consonant; otherwise, it will not be considered as a diphthong but a sequence of vowels and semi-vowels each of which belongs to a different syllable.

Diphthongs are two: ai (ay) au (aw)

Table 13. Distribution of Arabic diphthongs

\begin{tabular}{ll}
\hline Final position & Medial position \\
\hline law 'if' & 'awn 'help, assistance' \\
\hline kay 'in order to' & 'ayn 'an eye' \\
\hline & yaum/yawm 'a day' \\
\hline nawm & 'sleeping' \\
\hline kayd/kaid & 'cunning, trick, plot \\
\hline Sayd & 'hunting, fishing' \\
\hline tayt/bait & house \\
\hline taHaywayada & 'to become a jew' \\
\hline
\end{tabular}

\subsection{Nasalized Arabic Vowels}

All six vowels in Arabic are phonetically nasalized when contiguous with a nasal consonant. Examples are:

Table 14. Nasalization in Arabic

\begin{tabular}{ll}
\hline /bint/ & 'daughter' \\
\hline /fursa:n/ 'horseman' & \\
\hline /sala:m/ 'greeting' & \\
\hline /xamsi:n/ & 'fifty' \\
\hline
\end{tabular}

Thus, we find that the vocalic system of Arabic is much simpler than that found in many other Semitic languages. However, the possibility of deviation from the classical pronunciation cannot be ruled out in different varieties of modern Arabic. For example, a final distributional difference between Modern Arabic and Classical Arabic is the treatment of final long and short vowels. No modern variety of Arabic exhibits a contrast between long and short final vowels on the pattern of Classical forms (Jones, 1965). Like in:

Table 15. An example of a vocalic pattern in Classical Arabic

\begin{tabular}{l}
\hline /kita:bi:/ 'my book' \\
\hline /kita:bi/ 'book' \\
\hline
\end{tabular}


This simply indicates that the vocalic pattern of Classical Arabic is under change and therefore vowel contrast is being modified. In general, vowel substitution and restitution is perhaps the most common way in which dialectal Arabic varieties are assimilated to their classical cognate (Haywood \& Nahmad, 1965).

\section{Conclusion}

Arabic is one of the most prominent languages of the Hamitic branch of the Afro-Asiatic family also called the Hamito - Semitic family. It is an infixing language in which word-formation involves predominantly infixing vowels in a root consisting entirely of consonants.

The Arabic vocalic system mainly revolves around six vowels and two diphthongs. Six pure vowels out of which three are long and the other three are short. All six vowels in Arabic are phonetically nasalized when they are contiguous with nasal consonants.

Thus, we find that the vocalic system of Arabic is much simpler than that found in many other Semitic languages.

Finally, since the vowels of Modern Standard Arabic are hardly at acoustic extremes, their use as a reference tool is as limited as those of other varieties of Arabic.

\section{References}

Abboud, P. (1984). Elementary modern standard Arabic. Cambridge, UK: Cambridge University Press. DOI: $10.1017 / \mathrm{CBO} 9781139168281$.

Abercrombie, D. (1967). Elements of general phonetics. Edinburgh, UK: Edinburgh University Press.

Al-Ani, S. (1970). Arabic phonology. The Hague, Netherland: Mouton Publishing. DOI: $10.1515 / 9783110878769$.

Chejne, A. (1958). The role of Arabic in present day Arab society. The Islamic Literature, 10(4), 15-54.

Clements, G. N. (1991). Place of articulation in consonants and vowels: A united theory. Working Papers of the Cornell Phonetics Laboratory, 1(5), 77-123.

Crothers, J. (1978). "Typology and Universals in Vowel Systems". In: Greenberg (Ed.), Universal of human language (93-152). Stanford, CA: Stanford University Press.

Fatihi, A. R. (2001). Aspects of Arabic phonology. New Delhi, India: Katinga Publishing.

Greenberg, J. (1978). Universals of human language. Stanford, CA: Stanford University Press.

Haywood, J. A. \& Nahmad, H. M. (1965). A new Arabic grammar of the written language. London, UK: Lund Humphries Publishing.

Holes, C. (1990). Gulf Arabic. London, UK: Routledge Publishing.

Hualde, J. I. (1991). Unspecified and unmarked vowels. Linguistic Inquiry, 22(1), 205-209.

Jones, D. (1965). An outline of English phonetics, $\left(8^{\text {th }}\right.$ Edition). Cambridge, UK: Haffer Publishing. DOI: $10.2307 / 410583$

Karin, C. R. (2006). A reference grammar of modern standard Arabic. Cambridge, UK: Cambridge University Press.

Lindan, M. (1978). Vowel features. London, UK: Oxford University Press.

Wright, W. (1977). A grammar of the Arabic language, ( $3^{\text {rd }}$ Edition). Cambridge, UK: Cambridge University Press. 